\title{
Numerical Investigation of Unsteady Mixed Convection Heat Transfer In ventilated enclosure With Different Aspect Ratio
}

\author{
Ali A. Mohammed ${ }^{1}$ \\ Aliazzam89@yahoo.com \\ Amir S. Dawood ${ }^{1}$ \\ Amirsd1954@yahoo.com \\ ${ }^{1}$ Department Of Mechanical Engineering, University of Mosul, Mosul, Iraq \\ Address All Correspondence to Ali A. Mohammed
}

\begin{abstract}
Unsteady mixed convection heat transfer of a laminar fluid flow in ventilated enclosure was studied numerically. The bottom horizontal surface was considered isothermal, whereas the other walls were considered adiabatic. The fluid enters into enclosure through a hole located at the bottom of the left vertical wall and exits from the top of the opposite wall. The mathematical model is governed by two dimensional conservations of mass, momentum and energy equations. The numerical simulations of the fluid flow and heat transfer were investigated with a range of Reynolds number $(50-500)$ and Richardson number $(0-10)$, with Prandtl number fixed at 0.71. The effect of the aspect ratio on the fluid flow and heat transfer characteristics in the enclosure was studied in three different values $(0.5,1,1.5)$. The numerical results showed that the maximum value of the average Nusselt number was achieved at aspect ratio of 0.5 . Also, the average Nusselt number increases with the increase of Richardson and Reynolds numbers for whole different cases.
\end{abstract}

Keywords: Mixed convection, Ventilated enclosure, Aspect ratio, Richardson number.

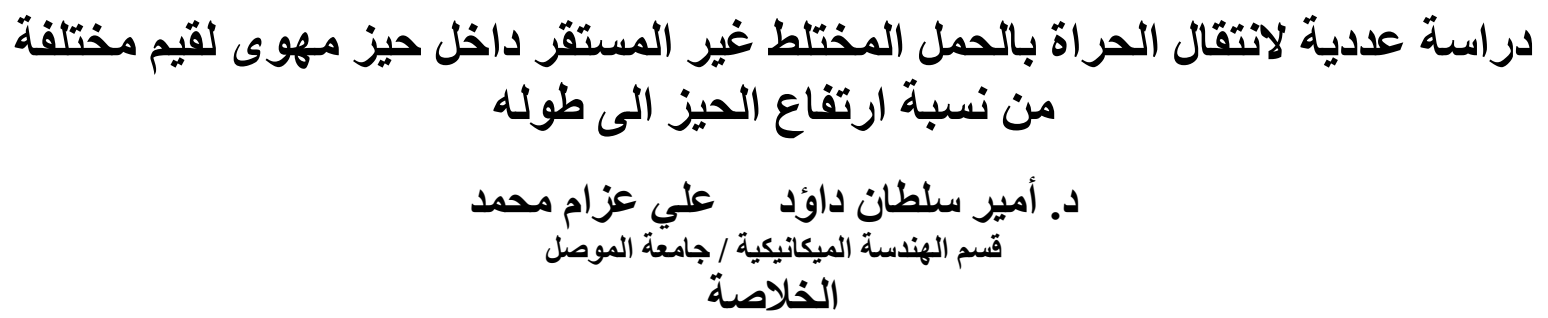

يقدم البحث دراسة عددية لانتقال الحرارة بالحمل المختلط غير المستقر لجريان المائع الطباقي في حيز مهوى. يعتبر

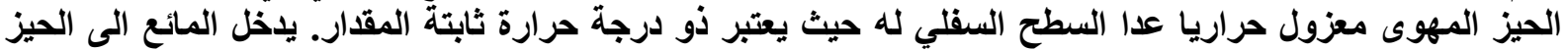

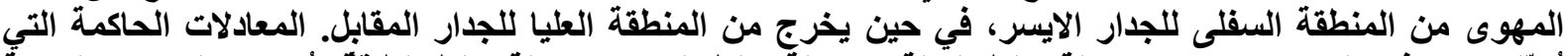

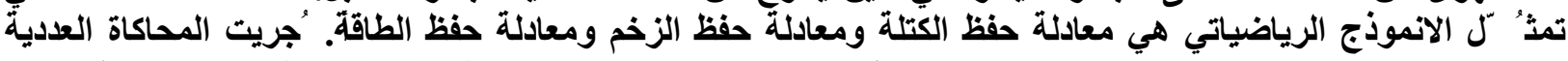

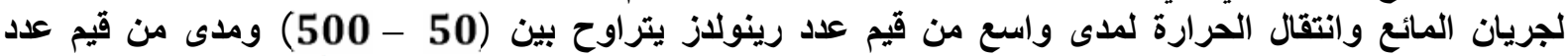

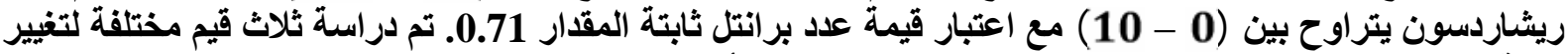

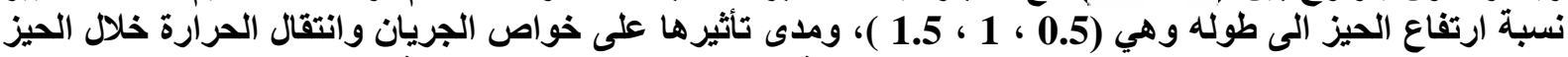

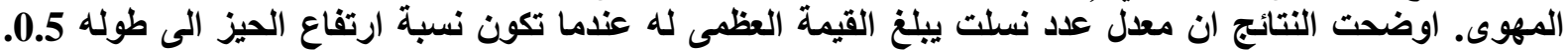

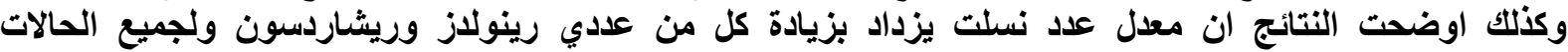
المدروسة.

Received: 25 - 3 - 2014 Accepted: $22-8-2015$ 


\begin{tabular}{|c|c|c|c|}
\hline \multicolumn{2}{|r|}{ Nomenclature } & \multicolumn{2}{|r|}{ Greek symbols } \\
\hline AR & Height to length aspect ratio & $\beta$ & Coefficient of thermal expansion( $1 / \mathrm{K})$ \\
\hline$c_{p}$ & Specific heat at constant pressure $(V \mathrm{~kg} . \mathrm{K})$ & $\rho$ & Density $\left(\mathrm{Kg}^{\prime} \mathrm{m}^{3}\right)$ \\
\hline$D$ & Height of the inlet and outlet ports $(\mathrm{m})$ & $\mu$ & Dynamic Viscosity $(\mathrm{kg} / \mathrm{m} . \mathrm{s})$ \\
\hline$g$ & gravitational acceleration $\left(m^{\prime} s^{2}\right)$ & $v$ & Kinematic viscosity, $v=(\mu / \rho)$ \\
\hline$H$ & Height of the enclosure $(\mathrm{m})$ & $\psi$ & Stream function $\left(\mathrm{m}^{2 /} \mathrm{s}\right)$ \\
\hline$h$ & $\begin{array}{l}\text { Convective heat transfer coefficient } \\
\left(W^{\prime} m^{2} k\right)\end{array}$ & $\psi$ & Dimensionless Stream function \\
\hline$k$ & Thermal conductivity of the fluid $\left(W^{\prime} m K\right)$ & $\omega$ & Vorticity $(1 / s)$ \\
\hline $\mathrm{L}$ & Length of the enclosure $(\mathrm{m})$ & $\omega$ & Dimensionless Vorticity \\
\hline$n$ & normal to surface & $\tau$ & non-dimensional time \\
\hline $\mathrm{Nu}$ & Nusselt number & \multirow{2}{*}{\multicolumn{2}{|c|}{ Subscripts }} \\
\hline$p$ & Pressure $\left(N^{\prime} m^{2}\right)$ & & \\
\hline$P$ & non-dimensional pressure & av & Average \\
\hline $\operatorname{Pr}$ & Prandtl number & $f$ & Fluid \\
\hline $\operatorname{Re}$ & Reynolds number & $h$ & Hot \\
\hline $\mathrm{Ri}$ & Richardson number & $i$ & Inlet \\
\hline$S$ & Real length of the hot surface $(m)$ & $o$ & Outlet \\
\hline $\mathrm{T}$ & Temperature $\left(C^{\circ}\right)$ & o & Standard conditions \\
\hline$u, v$ & velocity components $\left(m s^{-1}\right)$ & & \\
\hline$U, V$ & non-dimensional velocity components & & \\
\hline$x, y$ & Dimensional Cartesian coordinates $(\mathrm{m})$ & & \\
\hline$X, Y$ & non-dimensional Cartesian coordinates & & \\
\hline$t$ & Time $(s)$ & & \\
\hline$u_{i}$ & Velocity of the forced flow at the inlet $\left(m s^{-1}\right)$ & & \\
\hline
\end{tabular}

\section{Introduction}

Mixed convection flow and heat transfer in a ventilated enclosure was studied extensively during the past several decades because of the wide range of its applications in many transport processes in nature and in engineering devices. These applications include heat exchangers, nuclear reactors, cooling of electronic systems and thermal environmental control of dwelling. In most of real applications there is imposed flow in addition to the buoyancy effect. Therefore the effect of the forced and natural convection on the fluid flow and heat transfer characteristics must be studied at the same time, and this is called the Mixed Convection. Forcing the flow in the same direction of the buoyancy force may assist the natural convection. In Such case, it is called Aiding Mixed Convection. Whereas when a fluid is forced in the opposite direction, its case is called Opposing Mixed Convection.

Angirasa [1] Studied unsteady mixed convection in adiabatic enclosure with an isothermal left vertical wall numerically. He studied both cases: Aiding and Opposing imposed flow. The results showed that the heat transfer was augmenting with increases of Reynolds number. Mahmud \& Pop [2] Numerically investigated the nature and the basic characteristics of the steady aiding and the opposing mixed convection in a ventilated square cavity filled with porous medium. The obtained results showed that the inlet width to the enclosure height ratio considerably affects the flow and the heat transfer characteristics in the cavity, also the results showed that the global heat transfer into the enclosure is sensitive to the change of it for fixed values of the parameters Ra and Pe. Saha et.al [3] Numerically studied the mixed convection heat transfer in ventilated enclosure with a constant heat flux from uniformly heated bottom 
wall. Four different locations of inlets and outlets are introduced to analyze the effect of the heat transfer in the enclosure in addition to some of governing parameters. The results similar heat transfer process at the exit for both BT (Bottom to Top) and TB (Top to Bottom) configurations. Saha et.al [4] numerically studied a double diffuse mixed convection in a ventilated square cavity with three different positions of the exit port. The results indicated significantly the effect of the position of the exit hole. Papanicolaou and Jaluria [5-8] did a series of numerical investigations for mixed convection in an adiabatic enclosure with isothermal sources. The optimal location for best cooling of the heated component, laminar, transitional and turbulent flows, was examined, by watching applications used for cooling of electronic components located in a rectangular enclosure. Islam et. al [9] numerically studied mixed convection heat transfer in an adiabatic ventilated enclosure with a heat source located at the left side of the bottom wall. The results showed that the rate of heat transfer increases with the decrease of the heat source size and the increase of Grashof number.

Boudebous \& Nemouchi [10], Numerically investigated unsteady mixed convection in a ventilated enclosure with isothermal left wall. The results showed that the effect of Richardson on the flow and heat transfer is very similar in both cases. Saha et.al [11] Combined both free and forced convection from a flush mounted uniform heat source on the bottom of a horizontal rectangular enclosure with side hole is studied numerically. The computational results showed for $\mathrm{Ri}>1$, that the heat transfer is dominated by natural convection, For $\mathrm{Ri}<1$ the flow and heat transfer are dominated by forced convection while the mixed regime formed when $\mathrm{Ri}=1$. Khanafer \& Vafai [12] Numerically studied an open ended enclosure for three different forced flow angles of attack. The researcher studied the effect of aspect ratio for wide range $(0.25-1)$. The results showed that the Nusselt number increased linearly with Reynolds numbers for the three configurations at low Grashof numbers and the horizontal flow could be used to insulate the cavity from the surrounding medium. leong et.al [13] numerically simulation of mixed convection from an open cavity in a horizontal channel with various aspect ratios. The results showed that there is a significant influence on the orientation of recirculating cells, while Reynolds and Grashof numbers control the flow pattern and the occurrence of these cells. Islam et.al [14] Numerically simulation of steady mixed convection heat transfer in an adiabatic parallelogrammic with ventilated enclosure with uniform heat source applied on the horizontal bottom wall. The study focused on the effect of the positive and negative inclination angle for the vertical side walls. The Results showed that the average value of Nusselt number increases with the increase of Richardson number for low values of positive and negative inclination angle, whereas it remains constant with Richardson number at high values of positive and negative inclination angle.

\section{The physical Model}

The model was represented by 2-D ventilated enclosure with three different aspect ratios ( $\mathrm{H} / \mathrm{L})$ as Sketched in Figure.1. The vertical side walls of length $(\mathrm{H})$ are adiabatic, while the bottom and upper horizontal walls of width (L) are isothermal and adiabatic respectively. The fluid enters to the enclosure through the inlet located at the bottom of the left vertical wall and exits from the top of the opposite wall. The ratio of $(\mathrm{D} / \mathrm{L})$ is 0.1 . 


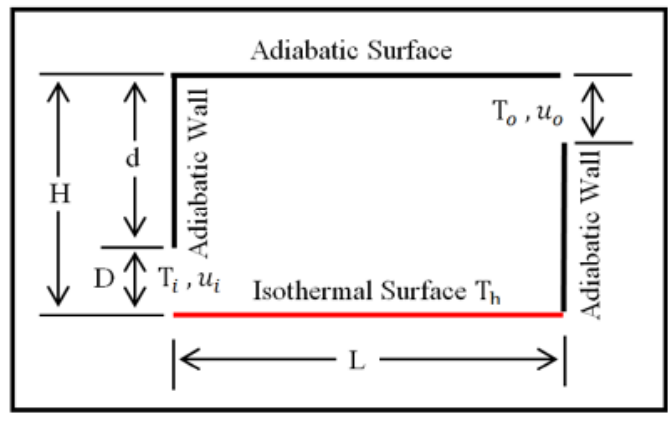

(a) $\mathrm{H} / \mathrm{L}=0.5$

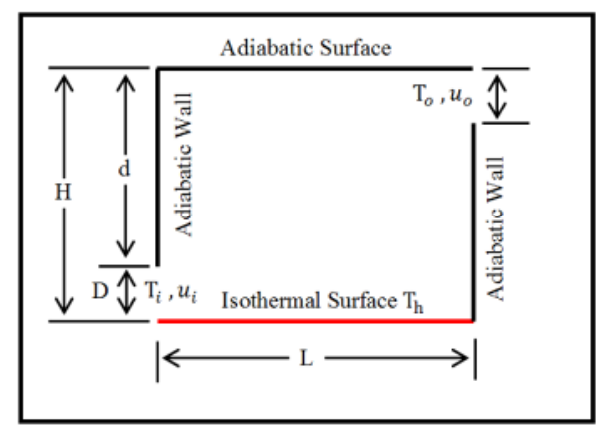

(b) $\mathrm{H} / \mathrm{L}=1$

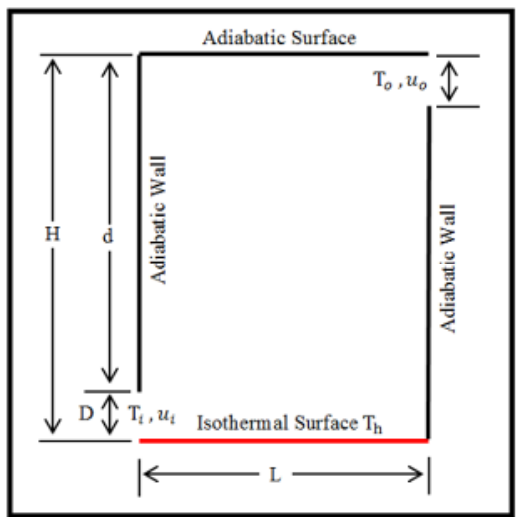

(c) $\mathrm{H} / \mathrm{L}=1.5$

Fig.1. The configurations of the present work

\section{The mathematical model}

\subsection{Governing equations}

The flow characteristics were assumed to be laminar, 2-D and incompressible flow. All physical properties of the fluid were assumed constant. The density variation as a function of temperature in the buoyancy term for which the Oberbeck - Boussinesq approximation was used [15]. As well as neglected the effect of the viscous dissipation.

$\rho_{f}=\rho_{o}\left[1-\beta\left(T-T_{o}\right)\right] \mathrm{g}$

According to above assumptions, the governing equations can be written in non-dimensional form as follows:

Continuity equation:

$\frac{\partial \mathrm{U}}{\partial X}+\frac{\partial V}{\partial Y}=0$

$\mathrm{X}$ - Momentum equation:

$\frac{\partial U}{\partial \tau}+(\mathbf{v} . \nabla) U=-\frac{\partial P}{\partial X}+\frac{1}{R e} \nabla^{2} U$

$\mathrm{y}$-momentum equation:[1][14] 
$\frac{\partial V}{\partial \tau}+(\mathbf{v} . \nabla) V=-\frac{\partial P}{\partial X}+\frac{1}{R e} \nabla^{2} V+R i . \theta$

Energy equation:

$\frac{\partial \theta}{\partial \tau}+U \frac{\partial \theta}{\partial X}+V \frac{\partial \theta}{\partial Y}=\frac{1}{R e . P r}\left[\frac{\partial^{2} \theta}{\partial X^{2}}+\frac{\partial^{2} \theta}{\partial Y^{2}} \mid\right.$

The non-dimensional terms and numbers are defined as follows:

$$
\begin{aligned}
& R e=\frac{\rho_{f} \cdot u_{i} \mathrm{~L}}{\mu_{f}}, \quad R i=\frac{\beta . \Delta T . \mathrm{L} \cdot g}{u_{i}^{2}}, \quad \operatorname{Pr}=\frac{\mu_{f} \cdot c_{p}}{k_{f}}, \quad \omega=\frac{\omega . \mathrm{L}}{u_{i}}, \quad \psi=\frac{\psi}{\mathrm{L} \cdot u_{i}} \\
& X=\frac{x}{\mathrm{~L}}, \quad Y=\frac{y}{\mathrm{~L}}, \quad U=\frac{u}{u_{i}}, \quad V=\frac{v}{\mathrm{u}_{\mathrm{i}}}, \quad \tau=\frac{t \cdot U_{i}}{\mathrm{~L}}, \quad \theta=\frac{\left(T-T_{i}\right)}{\left(T_{h}-T_{i}\right)}, \quad P=\frac{p}{\rho_{f} u_{i}^{2}}
\end{aligned}
$$

The non-dimensional momentum equations (3) and (4), are combined by cross-differentiation and subtraction one of them from the other to yield the vortices transport equation given by [1][ 16] :

$\frac{\partial \omega}{\partial \tau}+U \frac{\partial \omega}{\partial X}+V \frac{\partial \omega}{\partial Y}=\frac{1}{R e}\left[\frac{\partial^{2} \omega}{\partial X^{2}}+\frac{\partial^{2} \omega}{\partial Y^{2}} \mid+R i \cdot \frac{\partial \theta}{\partial X}\right.$

Where the Dimensionless Stream function equation function given by :

$\omega=-\nabla^{2} \psi$

3.2 The Initial and boundary conditions

To solve any partial differential equation, we have to specify the initial and boundary conditions for the dependent variables. The initial conditions for $(\omega, \psi, \theta)$ for all points of the Domain $(\Omega)$ of the ventilated enclosure at $\mathrm{t}=0$.

$$
\omega=\psi=\theta=0 \text { on } \Omega \text { at } \mathrm{t}=0
$$

The appropriate boundary conditions $(\Gamma)$ for the present study at $t>0$, is given in Table- 1 .

\begin{tabular}{|c|c|c|c|}
\hline & Stream function $(\psi)$ & Vortices $(\omega)$ & $\begin{array}{c}\text { Temperature } \\
(\theta)\end{array}$ \\
\hline inlet & $\psi=Y$ & 0 & 0 \\
\hline outlet & $\partial \psi / \partial n=0$ & $\partial \omega / \partial n=0$ & $\partial \theta / \partial n=0$ \\
\hline Left wall & $\bar{\psi}=\overline{\mathrm{D}}$ & $\begin{array}{c}\omega=-\partial^{2} \psi ; \partial n^{2} \& \\
\partial \psi / \partial n=0\end{array}$ & $\partial \theta / \partial n=0$ \\
\hline $\begin{array}{l}\text { Right } \\
\text { wall }\end{array}$ & $\psi=0$ & $\begin{array}{c}\omega=-\partial^{2} \psi^{\prime} \partial n^{2} \& \\
\partial \psi / \partial n=0\end{array}$ & $\partial \theta / \partial n=0$ \\
\hline $\begin{array}{l}\text { Upper } \\
\text { surface }\end{array}$ & $\psi=\mathrm{D}$ & $\begin{array}{c}\omega=-\partial^{2} \psi^{\prime} \partial n^{2} \& \\
\partial \psi / \partial n=0\end{array}$ & $\partial \theta / \partial n=0$ \\
\hline $\begin{array}{l}\text { Lower } \\
\text { surface }\end{array}$ & $\psi=0$ & $\begin{array}{c}\omega=-\partial^{2} \psi^{\prime} \partial n^{2} \& \\
\partial \psi / \partial n=0\end{array}$ & $\theta=1$ \\
\hline
\end{tabular}
No slip and penetration boundary conditions are adopted.

Table-1. The appropriate boundary conditions 


\subsection{Calculations of Heat transfer}

The local rate of heat transfer along the hot surface can be represented by Nusselt number,

$N u=\frac{h}{k^{\prime} \mathrm{L}}=-\frac{\partial \theta}{\partial n}$

While the average heat transfer at the hot surface can be calculated by average Nusselt number along it,

$$
\begin{aligned}
& N u_{a v}=\frac{1}{s} \int_{0}^{\mathrm{s}} N u \cdot d s \\
& s=\int_{0}^{\mathrm{L}} \sqrt{1+\left(\frac{d Y}{d X}\right)^{2}} \cdot d X
\end{aligned}
$$

\section{Numerical Procedures}

To solve the governing partial differential equations (5-7), must be transformed it to simple algebraic equations by using the finite difference methods, then solve these equations by using one of the numerical techniques such as Alternating Directions Implicit (ADI) method with relaxation factor (Hoffman)[17].

The grid generation technique allow to reduce the mesh size. Reducing the mesh size leads to increase of the convergence in calculations to get the desired results and to achieve the criteria of tolerance. i.e. reducing in the elapsed time for each iteration to get the steady state condition. This reduction in the elapsed time leads to a reduction in the energy consumption for computers, especially for the super computers with multiprocessors. These benefits may be included by numerical cost. As well as to minimize the rounding error resulting from using the finite difference approximation, and to give great accuracy in the results obtained from the numerical solution. In the current study was used Poisson's equations to create a nonorthogonal elliptic grid, and used the method developed by (Thomas and Middlecoff) [18], to give the estimated values of the functions that control the distribution of the grid liens. The resulting grid from the present work can be illustrated in fig. 2 . To increase the density of the grid in the region of the high gradient of properties, we must use a suitable cluster function ((Petrović \& Stupar) [19], Such as those used in the regions of fluid entry, exit and near the boundaries, as illustrated in figure.2. The convergence criteria for all dependent variables are $10^{-7}$. The code of the program was created by using the Matlab software (M-file).

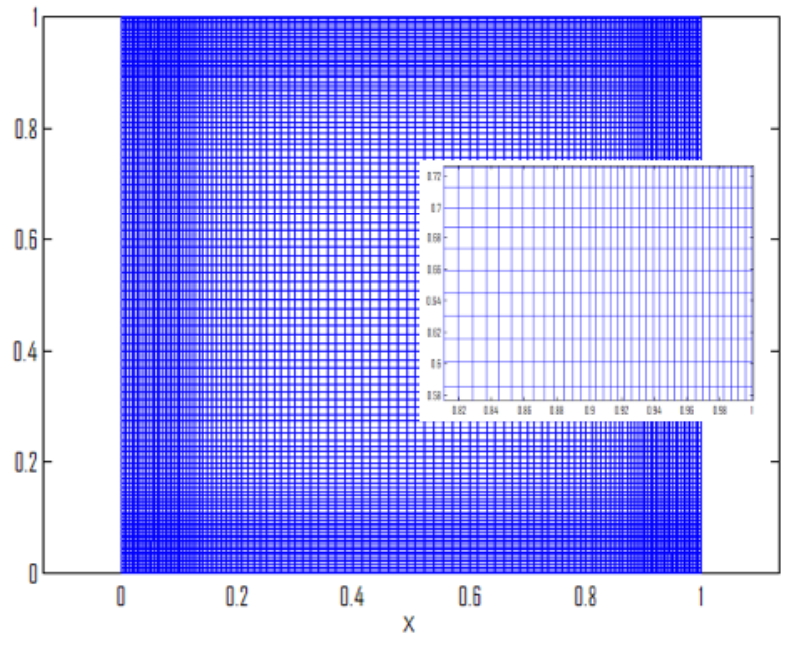

Fig.2. The mesh used in present work

\section{Grid sensitivity and Code validation}

In the present study, five Combinations of the non-uniform grids were used to test the effect of the mesh size on the accuracy of the results, as illustrated in Table-2. The results show more accuracy for the large size of mesh, where the maximum percentage of difference in the numerical results was (3.61\%) ranging between (50X50) and (120X120), whereas the 
minimum difference in the numerical results was $(0.44 \%)$ ranging between (100X100) and (120X120). To compare between the percentage of difference and the elapsed time by CPU, the mesh size (100X100) was used for all calculations.

Table-2. Average Nusselt number for $\mathrm{H} / \mathrm{L}=1, \mathrm{Re}=100$ and $\mathrm{Ri}=10$

\begin{tabular}{|c|c|}
\hline Mesh size & $N u_{a v}$ \\
\hline $50 \times 50$ & 7.696 \\
\hline $70 \times 70$ & 7.7183 \\
\hline $90 \times 90$ & 7.7221 \\
\hline $100 \times 100$ & 7.7277 \\
\hline $120 \times 120$ & 7.7321 \\
\hline
\end{tabular}

The numerical code were validated with the previous studies by Angirasa [1], and Saeid \& Pop [20], as illustrated in figure.3 and figure.4. respectively. Good agreement was achieved for both the streamlines and isotherms. Also, the average Nusselt number was compared with previous study by Angirasa [1] for different values of Richardson number. See Table-3.
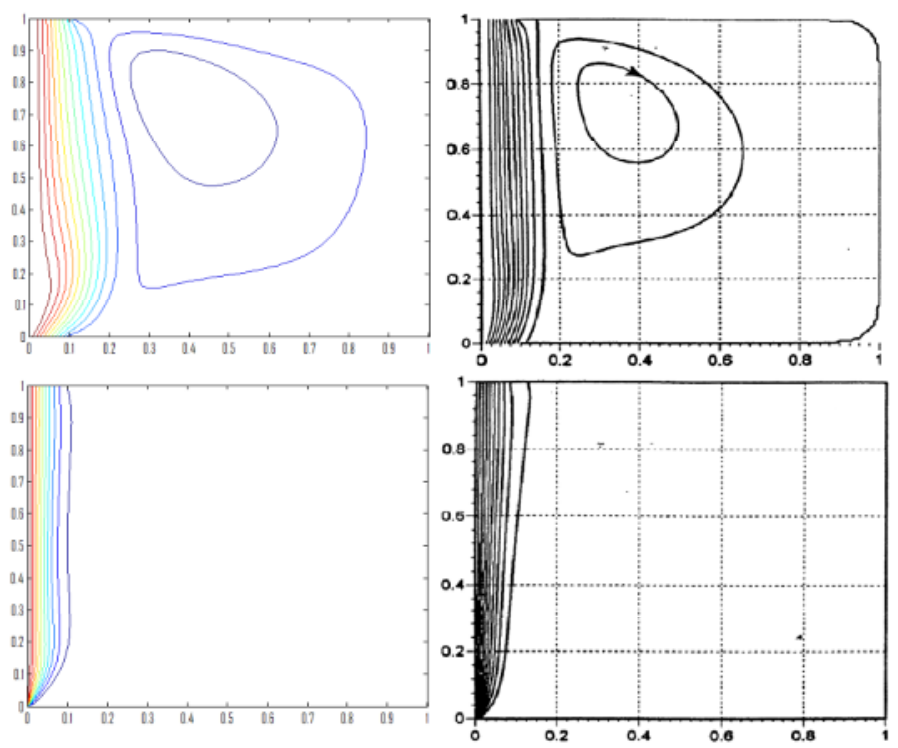

Present Work

Angirasa [1]

Fig.3. Streamlines (Upper) and isotherms (Lower) at $\mathrm{Gr}=10^{6}, \mathrm{Pr}=0.7$ and $\mathrm{Ri}=2$ 

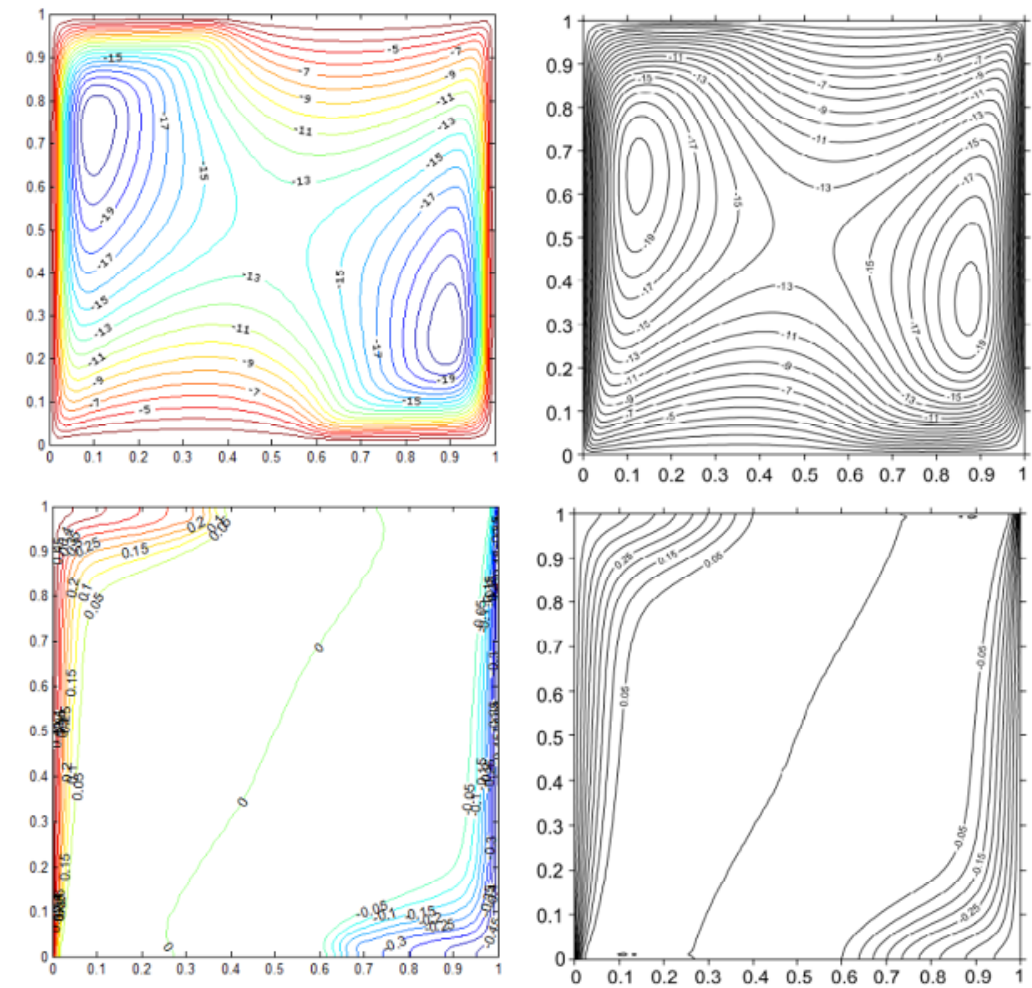

Present Work

Saeid and Pop [20]

Fig.4. Streamlines (Upper) and isotherms (Lower) at $\mathrm{Ra}=1000$ and $\tau=0.0025$

Tabel-3. Average Nusselt number for validation at $\mathrm{Gr}=10^{6}, \operatorname{Pr}=0.7$. Angirasa[1]

\begin{tabular}{|c|c|c|}
\hline $\mathrm{Ri}$ & Angirasa [1] & Present work \\
\hline 0.5 & 18.897 & 18.882 \\
\hline 1 & 18 & 17.963 \\
\hline 2 & 16.989 & 16.897 \\
\hline 5 & 15.670 & 15.678 \\
\hline
\end{tabular}

\section{Results and Discussion}

Figure.5.a. shows the effect of $\mathrm{Ri}$ and Re numbers on the streamlines and Isotherms for aspect ratio 0.5 . At $\mathrm{Re}=50$, for low values of $\mathrm{Ri}(0-1)$, no recirculating cells appear in the enclosure, therefore the effect of natural convection is absence and the forced convection dominates the heat transfer in the enclosure. The gradual increase of $\mathrm{Ri}$ to 10 made the recirculating cell appear at the left upper corner of the enclosure as an indication to the effect of the natural convection regime in the enclosure. 
At $\mathrm{Re}=500$ and $\mathrm{Ri}=0$, two recirculating cells with opposite direction of angular motion appear in the enclosure. The first one appeared due to the effect of buoyancy force, it is small and located at the upper corner of the enclosure. The second one appeared due to the high inertia of imposed flow, it is larger than the first one and located at the right lower corner of the enclosure. As increase of $\mathrm{Ri}$ to 1 , the upper recirculating cell grows and directs the fluid flow down towards the bottom surface, this led to the absence of the lower cell. By increasing Ri to 10 , the recirculating cell developed and filled the upper half of the enclosure, indicating to the large effect of the natural convection to transfer heat in the enclosure. Also the fluid amount which in contact with the bottom hot surface, increases. As shown in fig.8.

At $\mathrm{Re}=50$, and for all values of Ri number. The temperature distributes over all the entire enclosure, especially at the right lower corner. As illustrated in fig.5.b. At $\mathrm{Re}=500$ and $\mathrm{Ri}=0$, the lower recirculating cell lead to increase the fluid motion and assisted to transfer the heat from the lower surface to the fluid. By increasing Ri to 10, the temperature distribution at the right lower corner of the enclosure decreases, because of large quantity of fluid passes over the hot surface, indicating to good heat transfer.

The effect of Re and Ri numbers on the streamlines contours for aspect ratio of 1 , is illustrated in fig.6.a. we can see that at low value of $\mathrm{Re}$ and $\mathrm{Ri}=0$, no circulating cell is in the enclosure, therefore the forced convection dominates the heat transfer in the enclosure. At $\mathrm{Ri}=1$, the small recirculating cell located at the left upper corner of the enclosure, indicates the effect of the natural convection, while the forced convection still dominates the heat transfer in the enclosure. While a gradual increasing of $\mathrm{Ri}$ to 10 , the development and growth of the recirculating cell lead to the increase the effect of the natural convection. At $\mathrm{Re}=500$ and $\mathrm{Ri}=0$, two recirculating cells appear. The first one is with anticlockwise direction of angular motion, located at the left upper corner of the enclosure. The second one located at the right lower corner, is with clockwise direction of angular motion. At $\mathrm{Ri}=1$, the upper recirculating cell grows and occupies the upper half of the enclosure, while the lower one gradually vanishes. At $\mathrm{Ri}=10$, the lower recirculating cell is completely absence and the upper one directs the imposed flow down toward the bottom hot surface, and this leads to the increase of the amount of fluid passes over the heat source.

At $\mathrm{Re}=50$, and for $\mathrm{Ri}\left(\begin{array}{ll}0 & -1\end{array}\right)$.The temperature distributes over all the entire enclosure, especially at the right lower corner of the enclosure. as illustrated in fig.6. At $\mathrm{Ri}=10$, the recirculating cell results in increasing the fluid motion, therefore the heat concentrated at the right lower corner decreases, indicating to the increase of the rate of heat transfer. At $\mathrm{Re}=500$ and $\mathrm{Ri}=0$, the lower recirculating cell lead to the increase of the fluid motion and assist to transfer the heat from the lower surface to the fluid. At $\mathrm{Ri}=10$, the large recirculating cell filled the upper half of the enclosure, therefore the isotherms are clustered at the lower half of the enclosure near the bottom hot surface, while the upper half of the enclosure remains unchanged.

Figure.7. shows the effect of Ri and Re on the streamlines and isotherms. At low value of Re and $\mathrm{Ri}$, the heat transfer in the enclosure is dominated by forced convection. At $\mathrm{Ri}=1$, the large recirculating cell located at the upper top corner of the enclosure, indicates the large effect of natural convection as compared with the two previous cases. This shows clearly the effect of mixed convection heat transfer in the enclosure. At higher value of $\mathrm{Ri}$, the recirculating cell develops and completely fills the enclosure space, therefore the natural convection dominates the heat transfer in the enclosure. At higher value of $\mathrm{Re}$ and $\mathrm{Ri}=0$, the 
two recirculating cells of the opposite direction are obvious, the upper one, resulting from the buoyancy force, is small as compared with the second one which is resulted from the force of inertia of the imposed flow, it lies at the lower part of the enclosure. At $\mathrm{Ri}=1$, the upper recirculating cell grows and develops, indicating to the increase of the effect of natural convection. The lower recirculating cell decays gradually. At $\mathrm{Ri}=10$, the upper recirculating cell occupies the entire space of the enclosure and the imposed flow for a thin layer passes the heat source.

Figure.7.b. shows the effect of $\mathrm{Ri}$ and $\mathrm{Re}$ on the isotherms. At $\mathrm{Re}=50$ and for $\mathrm{Ri}(0-1)$, The isotherms distributes all over the entire enclosure, especially at the lower right corner of the enclosure. While increasing $\mathrm{Ri}$, the isotherms becomes non-linear as a result of recirculating cell existence which resulted from increasing of the effect of natural convection. At higher value of $\mathrm{Re}$ and for all values of $\mathrm{Ri}$, the isotherms concentrate near the hot bottom surface and decrease the temperature in the enclosure space, indicating to more heat transfer from the hot surface to the fluid flow.

Figure.8. shows the behavior of the average Nusselt number with time. For high values of Richardson and Reynolds numbers the flow exhibits high-frequency oscillations and the steady state cannot be achieved and the flow becomes more complicated. The steady state can be achieved for all cases with lower value of Richardson number.

At $\mathrm{AR}=0.5$ and lower value of $\mathrm{Re}$, the effect of $\mathrm{Ri}$ on the average Nusselt number is small, because the heat transfer in the enclosure is dominated by the forced convection. Large effect of Ri on the average of Nusselt number obtained at AR equals 1 or 1.5, indicating to the effect of natural convection on the heat transfer in the enclosure. As illustrated in fig.9.

At higher value of Re number, the average Nusselt number increases gradually due to the increase of $\mathrm{Ri}$ number for all cases, as a result of recirculating cells in the enclosure. This indicates that the mixed convection regime dominates the heat transfer in the enclosure. As illustrated in fig.9.

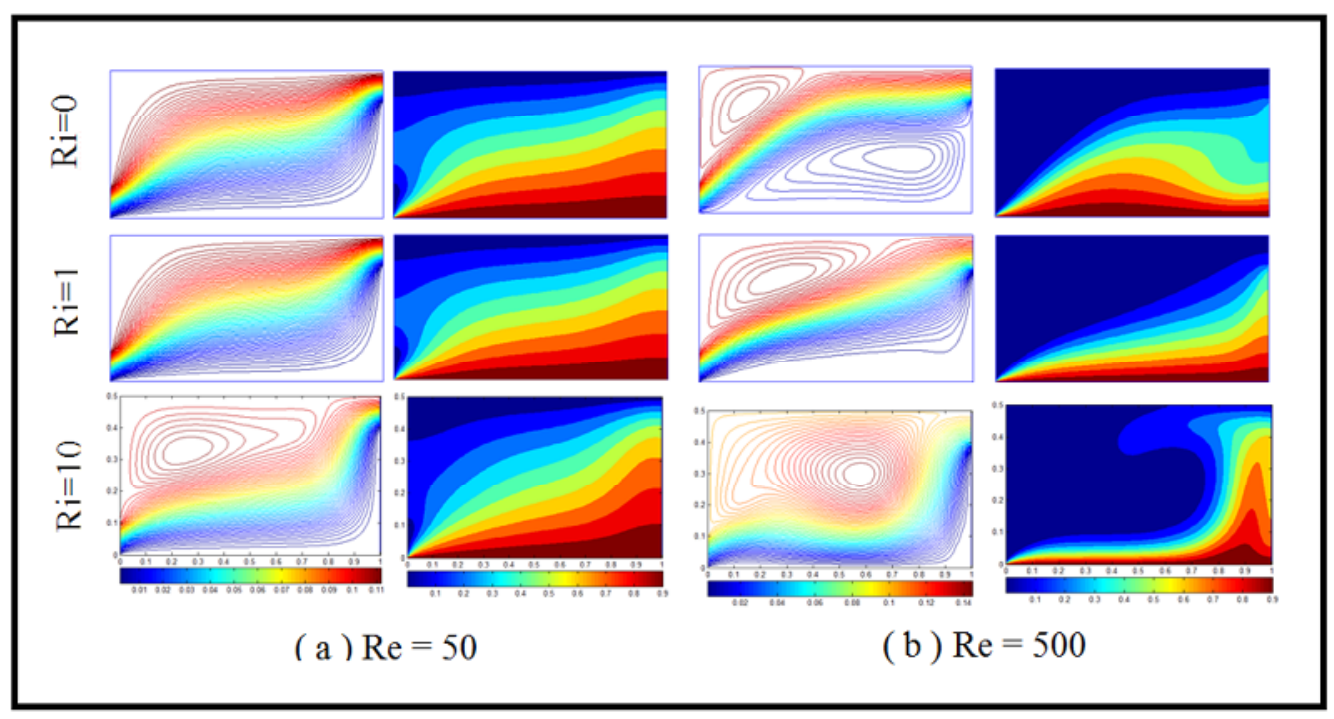

Fig.5. streamlines and isotherms at $\mathrm{AR}=0.5$ 


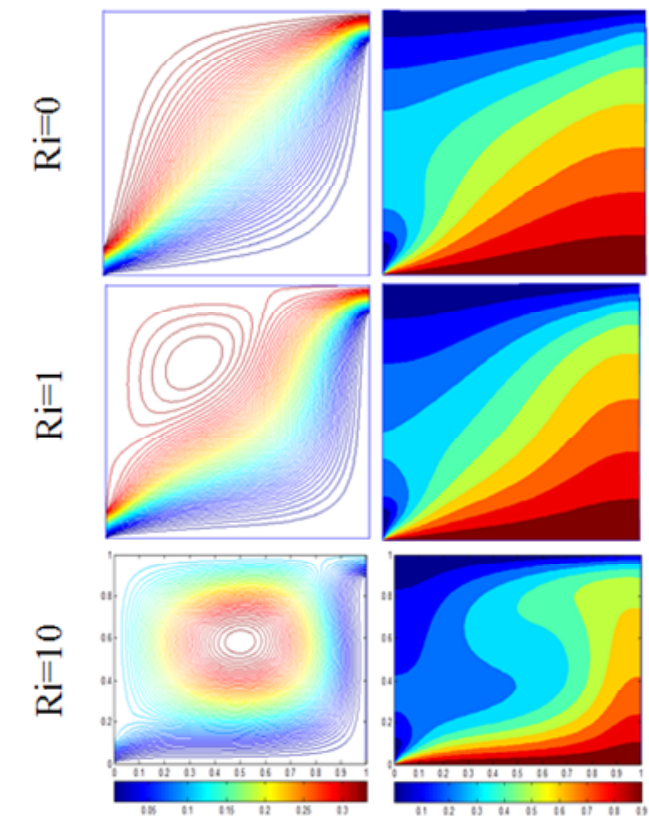

(a) $\operatorname{Re}=50$

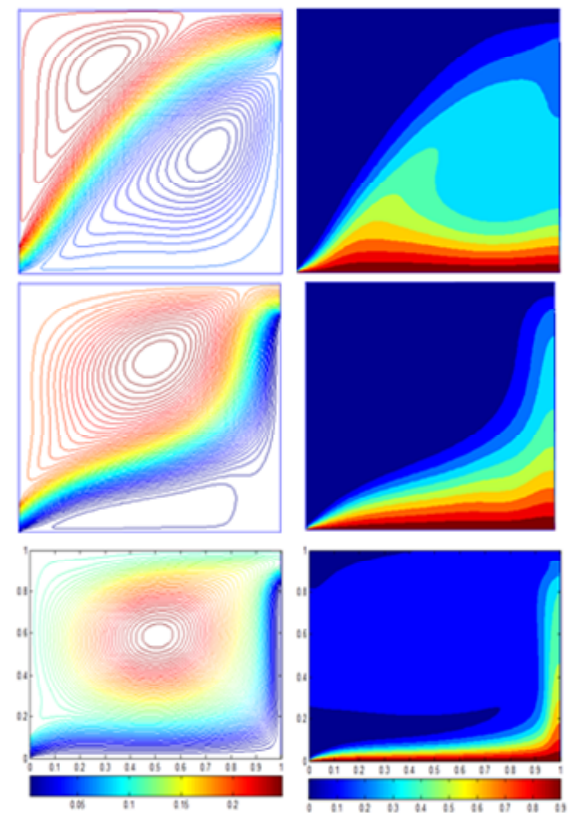

(b) $\operatorname{Re}=500$

Fig.6. streamlines and isotherms at $A R=1$

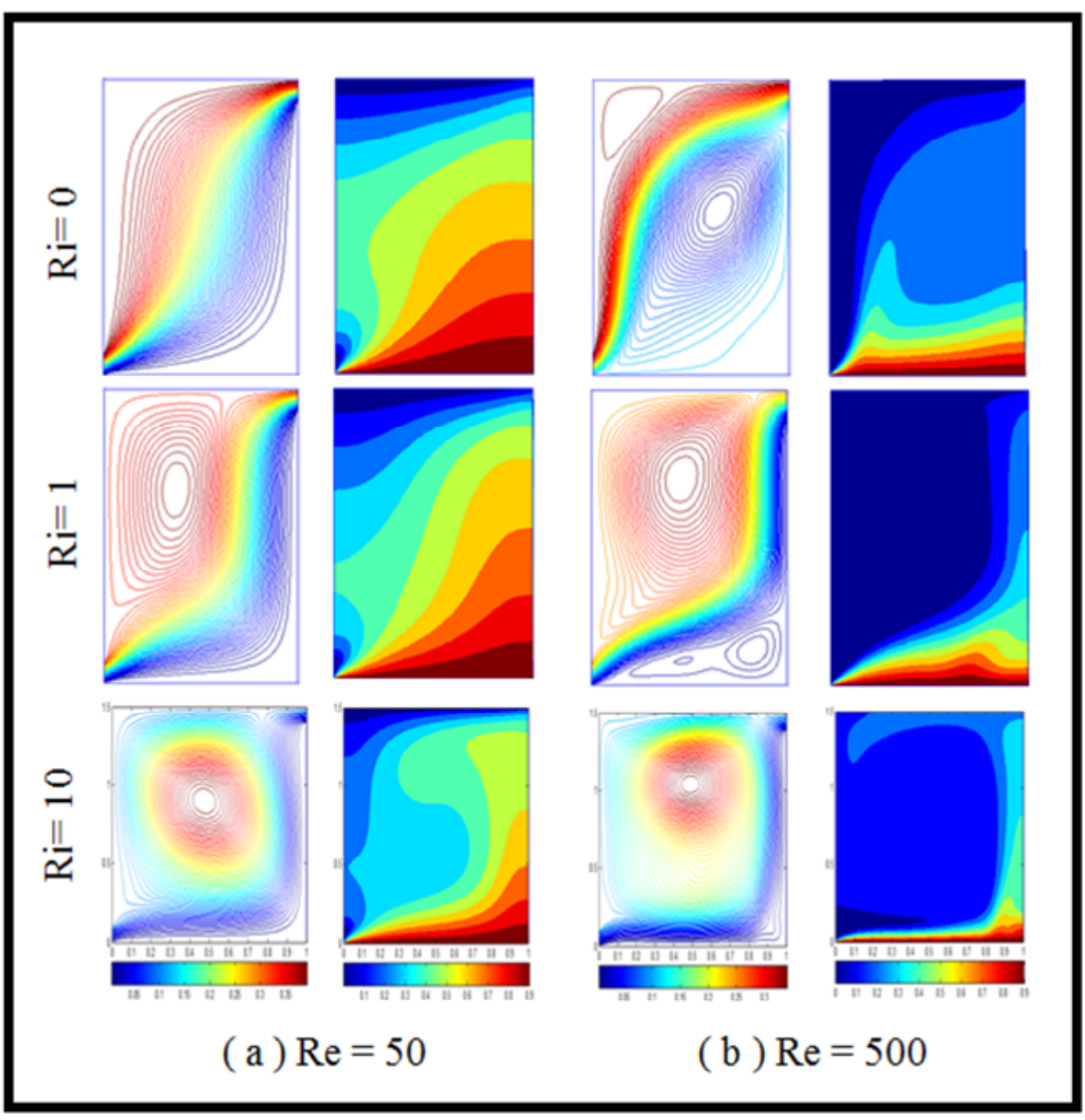

Fig.7. streamlines and isotherms at $\mathrm{AR}=1.5$ 


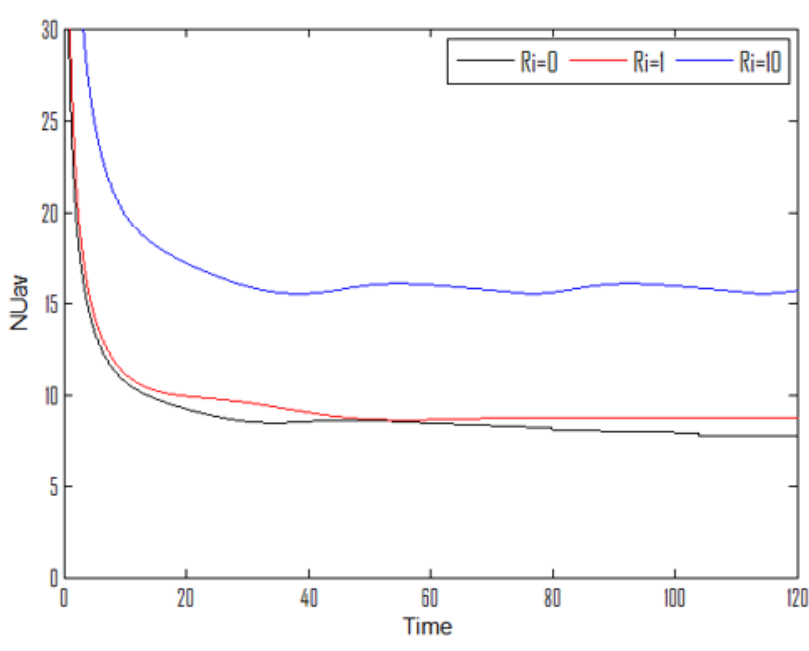

(a) $\mathrm{AR}=0.5$

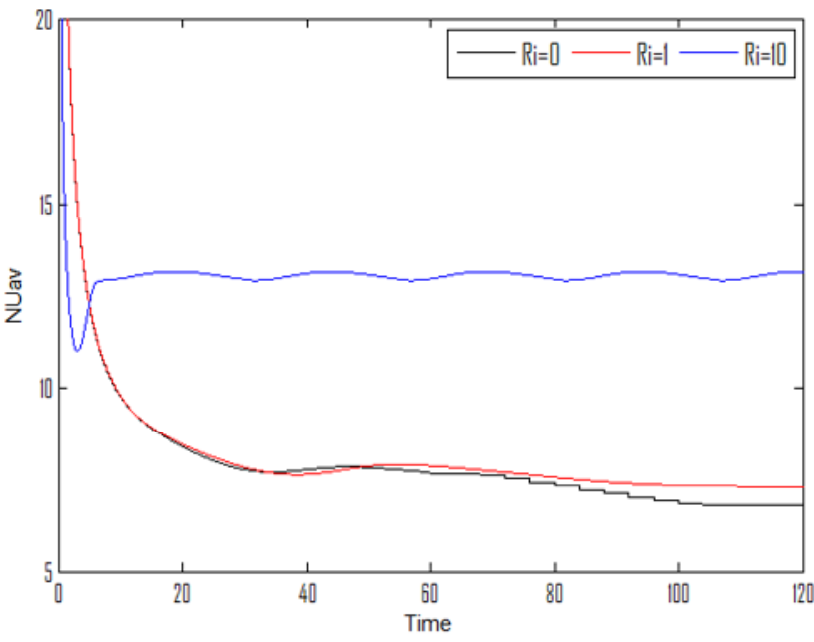

(b) $\mathrm{AR}=1$

Fig.8. Average Nusselt number with time for different values of $\mathrm{Ri}$ and $\mathrm{Re}=500$

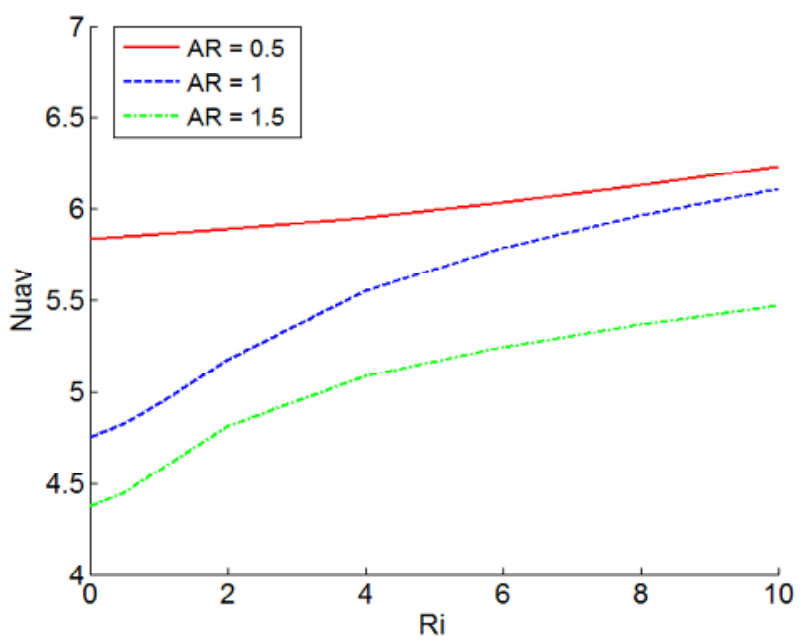

(a) $\operatorname{Re}=50$

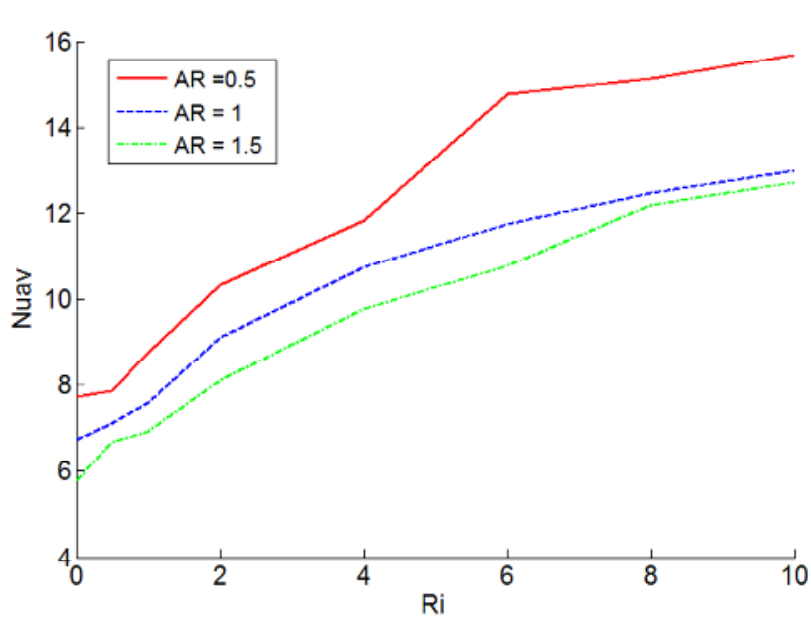

(b) $\operatorname{Re}=500$

Fig.9. Average Nusselt number with Ri

\section{Conclusion}

The Unsteady mixed convection heat transfer in a ventilated enclosure with different aspect ratios had been studied numerically. The numerical results showed that average Nusselt number increases with the increase of Richardson and Reynolds numbers for all different cases. At high values of Richardson and Reynolds numbers the unsteady periodic flow appears with high oscillation, i.e. there is no steady state achieved. Maximum value of average Nusselt number for all operation parameters is achieved at aspect ratio of 0.5 . The forced convection regime is dominating the heat transfer in the enclosure for different aspect ratio at Richardson number less than one. At Richardson number equals one, the mixed 
convection regime dominates the heat transfer at $\mathrm{AR}$ (1 and 1.5), whereas the forced convection regime still dominates the heat transfer at $A R=0.5$. The natural convection regime is dominating the heat transfer, for all different cases at Richardson number equals ten.

\section{References}

1- D. Angirasa., Mixed Convection In a Vented Enclosure With an Isothermal Vertical Surface, Fluid Dynamics Research 26 (2000) 219-233 and Elsevier science B.V.

2- Shohel Mahmud and Ioan Pop, Mixed Convection in a Square Vented Enclosure Filled With a Porous Medium, International Journal Of Heat and Mass Transfer 49 (2006) 21902206.

3- Sumon Saha, Tofiqul Islam, Mohammad Ali , Arif. Hasan Mamun and Quamrul Islam, Effect Of Inlet And Outlet Locations On Transverse Mixed Convection Inside a Vented enclosure, Journal Of Mechanical Engineering, Vol.ME36, Dec.2006.

4- Sumon Saha , Mohammad nasim Hasan and Iftheker Ahmed khan, Double Diffusive Mixed Convection Heat Transfer Inside a Vented Square cavity, Chemical Engineering Research Bulletin 13 (2009) 17-24.

5- Papanicolaou E. and Jaluria Y., Mixed Convection from an Isolated Heat Source in a Rectangular Enclosure, Numerical Heat Transfer, Part A. Vol. 18 ,(1990) p. 427461.

6- Papanicolaou E. and Jaluria Y., Transition to a Periodic Regime in Mixed Convection in a Square Cavity, J. Fluid Mech. Vol. 239 (1992) p. 489-509.

7- Papanicolaou E. and Jaluria Y., Mixed Convection from a Localized Heat Source in a Cavity with Conducting Walls, A Numerical Study, Numerical Heat Transfer, Part A. Vol. 23 (1993) p. 463-484.

8- Papanicolaou E. and Jaluria Y., Computation of Turbulent Flow in Mixed Convection in a Cavity with a Localized Heat Source, ASME J. Heat Transfer, Vol. 117 (1995) p. 649-658.

9- Tofiqul Islam, Sumon Saha, Arif Hasan Mamun, Computational Analysis Of Mixed Convection Heat Transfer In a Ventilated Enclosure, proceeding of the $3^{\text {rd }}$ BSME-ASME International Conference on Thermal Engineering 20-22 December, 2006, Dhaka, Bangladesh.

10- S .Boudebous and Z. Nemouchi, Heat Transfer by Unsteady Laminar Mixed Convection in 2-D Ventilated Enclosure Using Vorticity - Stream Function Formulation, WIT Transactions on Engineering Sciences, Vol53. (2006).

11- Sumon Saha , Goutam Saha, Mohammad Ali and Quamrul Islam, Combined Free And Forced Convection Inside A two-Dimensional Multiple Ventilated Rectangular Enclosure, Arpn J.of Engineering And Applied sciences. Vol.1, No.3, October 2006.

12- K. Khanafer, K. Vafai and M. Lightstone, Mixed Convection Heat Transfer in Two Dimensional Open Ended Enclosures, Int. J. Heat and Mass Transfer, Vol .45 (2002) p. 5171-5190.

13- Leong J.C., Brown N.M. and Lai F.C., Mixed Convection From an Open Cavity in a Horizontal Channel, Int. Comm. Heat and Mass Transfer, Vol. 32, (2005), p. 583592.

14- Tofiqul Islam, Sumon Saha , Goutam Saha, Mustafizur Rahman, Arif Hasan Mamun and Quamrul Islam, Numerical Simulation On Mixed Convection In a Parallelogrammic Ventilated Enclosure, GANIT. Bangladesh Math. Soc. (ISSN 1606-3694) 28 (2008) 45-58. 
15- Donald A. Nield and Adrian Bejan, (2006), Convection In Porous Media, Third Edition ,Springer Science - Business Media , Inc., New York, USA.

16- M. A. Waheed , G. A. Odewole and S. O.Alagbe , Mixed Convection Heat Transfer In Rectangular Enclosures Filled With Porous Media, ARPN Journal of Engineering And Applied Science, Vol.6,NO.8, August 2011.

17- Klaus A. Hoffmann and Steve T. Chiang, (2000), Computational fluid Dynamics I, a Publication Of Engineering Education System, Wichita, Kansas, USA.

18- P. D. Thomas and J. F. Middlecoff, Direct Control Of The Grid Point Distribution In Meshes Generated By Elliptic Equation, AIAA Journal., Vol 18 , PP 652-656, (1980).

19- Z. Petrovic and S. Stupar, (1996), Computational Fluid Dynamics I, Mechanical Engineering Faculty, University Of Belgrade.

20- Nawaf H. Saeid \& I. Pop., Transient free convection in a square cavity filled with a porous medium, International Journal of Heat and Mass Transfer 47 (2004) 1917-1924 